\title{
Lubrication of reciprocating seals : experiments on the influence of surface roughness on friction and leakage
}

\section{Citation for published version (APA):}

Kanters, A. F. C., \& Visscher, M. (1989). Lubrication of reciprocating seals : experiments on the influence of surface roughness on friction and leakage. In Tribological design of machine elements : proceedings, held at University of Leeds, 6-9 September 1988 / Ed. D. Dowson, C.M. Taylor, M. Godet (pp. 69-77). (Tribology : Leeds-Lyon symposium : proceedings; Vol. 14). Elsevier.

Document status and date:

Published: 01/01/1989

\section{Document Version:}

Publisher's PDF, also known as Version of Record (includes final page, issue and volume numbers)

\section{Please check the document version of this publication:}

- A submitted manuscript is the version of the article upon submission and before peer-review. There can be important differences between the submitted version and the official published version of record. People interested in the research are advised to contact the author for the final version of the publication, or visit the $\mathrm{DOI}$ to the publisher's website.

- The final author version and the galley proof are versions of the publication after peer review.

- The final published version features the final layout of the paper including the volume, issue and page numbers.

Link to publication

\section{General rights}

Copyright and moral rights for the publications made accessible in the public portal are retained by the authors and/or other copyright owners and it is a condition of accessing publications that users recognise and abide by the legal requirements associated with these rights.

- Users may download and print one copy of any publication from the public portal for the purpose of private study or research.

- You may not further distribute the material or use it for any profit-making activity or commercial gain

- You may freely distribute the URL identifying the publication in the public portal.

If the publication is distributed under the terms of Article 25fa of the Dutch Copyright Act, indicated by the "Taverne" license above, please follow below link for the End User Agreement:

www.tue.nl/taverne

Take down policy

If you believe that this document breaches copyright please contact us at:

openaccess@tue.nl

providing details and we will investigate your claim. 
Paper III(iii)

\title{
Lubrication of reciprocating seals: Experiments on the influence of surface roughness on friction and leakage
}

\author{
A. F. C. Kanters and M. Visscher
}

In the past, most theoretical work on reciprocating seals has been dedicated to the solution of the elastohydrodynamic lubrication (EHL) problem for smooth surfaces. However, measured friction forces and film thicknesses often do not support the hypothesis of full film lubrication. In the present paper, a first attempt is made to investigate the lubrication by experimental determination of friction forces and leakage using three rods with different surface roughness. An accurate method for leakage measurement has been developed because of the lack of accurate film thickness tranducers.

\section{INTRODUCTION}

The literature on reciprocating elastomeric seals exhibits many experimental data on their frictional behaviour. Regarding the dependency of the friction force at constant fluid pressure on the velocity or on the product of viscosity and velocity, it appears that reciprocating seals exhibit the characteristic behaviour depicted in fig. 1.

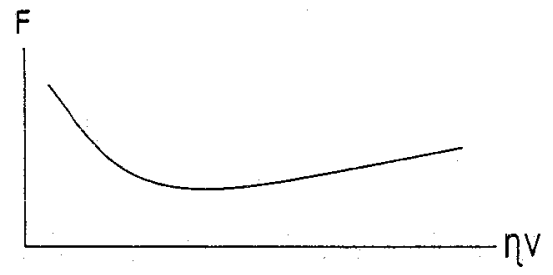

Fig. 1 Characteristic friction curve.

This curve is like a Stribeck curve. For constant viscosity it appears that with increasing speed the lubrication mode of the seal changes from boundary lubrication, via mixed lubrication, to full film lubrication. It has to be noted that it will depend on the specific seal design and experimental conditions whether the entire curve of fig. 1 will be obtained or not during an experimental program.

The tribological process in the seal contact constitues a classic elastohydrodynamic lubrication (EHL) problem if the seal is fully lubricated and if the influence of surface roughness is negligible. This problem is merely complicated by the large seal deformations and material behaviour. Most theoretical work on reciprocating seals has been devoted to the solution of the smooth EHL problem, e.g. (1), (2), (3), (4).
Yet in the early seventies Field and Nau obtained results which makes one reflect on the lubrication of the seal contact. From experiments on annular rubber rings of rectangular cross-section (5) they found that friction was of other than hydrodynamic origin. Nevertheless full lubricant films were observed, which would give rise to friction values by viscous shear at least an order of magnitude smaller. These results were verified in a number of subsequent papers (6), (7). A satisfactory explanation was not given. To our knowledge no further work has been reported on this matter. This is rather amazing since the results of Field and Nau imply the simultaneous occurance of a high friction and a high leakage.

We believe that further investigation into the lubrication of the seal contact is necessary. As a first step friction and leakage measurements on a polyurethan rod seal have been performed. To study the influence of surface roughness three rods have been used, each having a different surface finish.

\subsection{Notation}

d : rod diameter $[\mathrm{m}]$

$\bar{n}$ : average film thickness calculated from leakage data $[\mathrm{m}]$

$h_{1}$ : average thickness of leaked film [m]

h : film thickness at the position where the pressure gradient is zero [m]

1 : length over which oil is extracted $[\mathrm{m}]$

m : mass of the extracted oil [kg]

p : pressure $[\mathrm{Pa}$

q : flow per unit of width $\left[\mathrm{m}^{2} / \mathrm{s}\right]$

$\mathrm{v}$ : velocity $[\mathrm{m} / \mathrm{s}]$

$\mathrm{x}$ : coordinate $[\mathrm{m}]$

$\eta \quad$ : dynamic viscosity [Pas]

$\rho$ : specific weight $\left[\mathrm{kg} / \mathrm{m}^{3}\right]$ 


\section{TEST RIG}

The test rig has been designed for measurements on rod seals. The essential parts of the test rig are represented in fig. 2 .

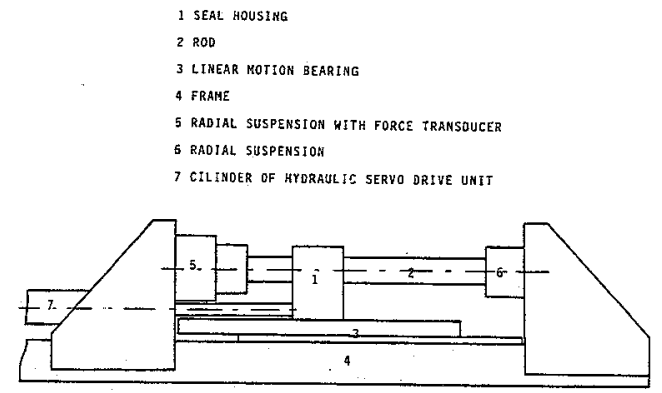

Fig. 2 Essential parts of the test rig.

The seal housing is moved along a stationary rod by a hydraulic servo drive unit and is externally guided by a high precision linear motion bearing, which ensures an accurate positioning between the seal housing and the rod. The seal housing consists of a body and two; easy exchangable, lids. A lid can be equipped with a nut to hold a seal (seal lid) or with a brass clearance bush (leak lid) (fig. 3).

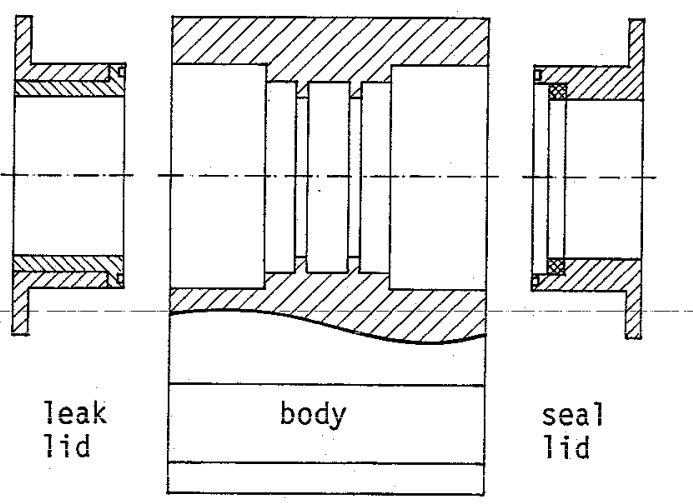

Fig. 3 Housing and lids.

The hydraulic servo drive unit consists of an actuator with very low internal friction, a hydraulic supply unit, an optical position transducer and a control module. It enables the accurate realisation of specific motion patterns over a maximum stroke length of 400 [mm]. The velocity can be varied from 0.5 until 750 [mm/s] with an accuracy of $0.5 \%$. The control module is linked to a personal computer. An interactive program enables user friendly communication. Automatic operation of an entire test program is possible.

The fluid pressure in the seal housing is applied by a separate hydraulic system, consisting of an electric pump, a buffer, and a cool. er. The desired pressure can be obtained by changing a bypass resistance. The pressure is measured by a standard transducer with strain gauges. Pressures up to 40 [MPa] can be realised. Even with a leak lid mounted in the seal housing, the pressure can be kept constant within 0.1 [MPa].
The temperature of the fluid in the seal housing is measured by a Pt thermo resistive transducer. The cooler keeps the temperature constant within $1[\mathrm{~K}]$.

\section{FRICTION FORCE MEASUREMENT}

The force, exerted by the seal housing on the rod, is measured by a standard force transducer positioned between the rod and the frame at the left hand side (fig. 2). The right hand side of the rod is radial suspended allowing free motion in axial direction. To eliminate disturbances by radial forces on the rod, the left hand side is suspended in the same way just to the right of the force transducer. The friction of the suspensions is negligible.

A relative motion of the rod out of the seal housing will be called an outstroke. A relative motion in the opposite direction will be called an instroke. The friction of a seal will in general depend on the direction of motion. Furthermore, different seals of the same type will not be completely identical and therefore exhibit somewhat different frictional characteristics. Hence, with two seal lids mounted in the housing, only a sum friction of a seal at outstroke and an other seal at instroke can be obtained.

To measure the friction of a single seal one seal lid has to be replaced by the leak lid, the friction of which can be calculated. However at seal outstrokes the clearance bush may become inadequately lubricated. Calculated friction values will then be unreliable. Friction at outstrokes of a certain seal A can alternatively be determined by subtracting the friction of a seal $B$ at instroke from the sum friction of seal $A$ at outstroke and seal $B$ at instroke.

\section{LEAKAGE MEASUREMENT}

Leakage is, in addition to friction and wear, an important practical parameter to classify the performance of a seal. Leakage along with friction measurements allow some conclusions to be drawn on the lubrication of the sealed contact. However, in this regard measurements of the film thickness throughout the sealed contact have to be preferred. In the past, investigators have tried to measure film thickness in several ways.

Schrader (8) used an iron pin, pressed against the seal surface by a non-ferro spring. The displacement of the pin was measured by an inductive transducer. Disadvantages of this method are among others an additional concentrated mechanical load on the relatively soft seal and a disturbance of the lubrication process at the measuring spot.

Field and Nau (5), (6), (7) and Austin, Flitney and Nau (9) measured the electric capacity over the lubricant film using rubber seals filled with carbon black. The specific resistance of the rubbers used was 2.78 [ $\Omega \mathrm{m}$ ] (9), which is low compared to the specific 
resistance of oil (about $10^{7}[\Omega \mathrm{m}]$ ). The errors in the measurements of Nau vary from about $3 \%$ at low film thicknesses $(0.25[\mu \mathrm{m}])$ to about 40 o at film thicknesses of $5[\mu \mathrm{m}]$, which is attributed to parasitive capacities in the electric circuit (5). Without explanation they report that the accuracy is pressure dependent. The errors at pressures above 8 [MPa] were estimated to be about 30 \% lower then the errors at lower pressures. This might be explained by influence of the pressure on the seal resistance.

Wernecke (10), (11) measured the electric resistance of the lubricant film. The electric conductivity of the rubbers (also filled with carbon black) would be sufficient according to (11). According to (10), however, it would not. This is amazing, for the same rubbers appear to be used in both publications. As in the papers by Nau e.a., no report is made on the influence of the seal resistance on the measurements. Wernecke also does not provide an accuracy of his measurements.

Measuring the film thickness by an elec. tric method is not as straightforward as it might appear and a thorough analysis of the applied method is essential. Often, the accuracy of the performed measurements is not very good. The electric resistance of the seal material must be low, which considerably limits the applicability of the method to commercial seals. Furthermore, due to the dimensions of the sensors (about $0.5[\mathrm{~mm}] ;(5)$ and (11)), although being small compared to the width of the sealed contact, only an average signal can be obtained. This may be acceptable under the condition of a full film throughout the entire contact, but may lead to misinterpretation of the results if the contact is only partially lubricated.

At the moment lubricant film thickness measurement is under fundamental investigation (12). However, a less complicated but accurate technique for the measurement of leakage has been developed, and used in practice. The technique is based on the extraction of leaked oil by solution in pure hexane. Next; the hexane and oil are seperated by vacuum evaporation, and the mass of the oil is weighed. Leakage at outstroke (out-leakage) can be obtained by extraction of the leaked fluid film that remains on the rod. The area from which the oil is extracted is defined by the distance between two bands of gummed tape applied to the rod. An average thickness of the leaked film may be calculated (see section 7).

Performed with the necessary carefulness this relatively simple method proves very reliable. To establish the accuracy of the method, several tests, described in sections 4.1 to 4.3 , have been performed.

\subsection{Rate of oil extraction.}

To test wether the oil film is fully extracted or only partly, oil has been applied to a smooth and clean plate of steel of known mass. After weighing the plate with oil, the oil has been extracted with hexane and the plate has been weighed again. The mass of it proved to be the same as the initial mass.

Also, the hexane and oil have been separated by vacuum evaporation and the oil has been weighed, showing a mass equal to the mass of the oil applied to the plate. Taking the dimensions of the plate and the accuracy of the mass measurement ( $\pm 0.1[\mathrm{mg}]$ ) into account, the remaining oil film thickness was less than 0.01 $[\mu \mathrm{m}]$.

\subsection{Influence of the gummed tape.}

The influence of the gummed tape has been determined in the following way. The mass of the clean steel plate and a piece of gummed tape fixed thereon has been weighed. Subsequently the plate has been washed with hexane and weighed again, showing an increase in mass. After removal of the tape and again weighing of the plate and tape, the mass had its initial value.

These results imply that there has been some hexane between tape and plate, which evaporated after removing the tape, and more important that no gum has been solved in the hexane.

\subsection{0il loss during vacuum evaporation.}

Some unsolved oil of known mass has been evaporated to determine the rate of oil loss during vacuum evaporation. It appeared to be less then $0.1 \%$ and is thus negligible.

\section{EXPERTMENTAL CONDITIONS AND TEST PROGRAM}

The seals used in the tests are polyurethan rings having a rectangular cross-section with a single rounded edge (fig.4).

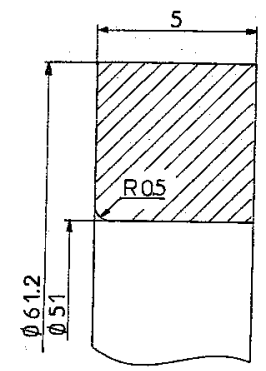

Fig. 4 Test seal.

The rings are mounted in a nut with a nominal diameter of $60[\mathrm{~mm}]$. During the tests the rounded edge of the seal has always been at the leading edge of the Iubricated contact (i.e. at oustroke measurements, the rounded edge was at the oil side and at instroke measurements at the air side). The nominal diameter of the rods is 50 [mm]. The fluid used is a normal hydraulic oil, Shell Tellus T46.

Thesurface roughness of the seal is identical to that of commercial seals made by injection moulding. Roughness profiles have been determined on a test rig enabling computer controlled measurements (13). An optical sensor has been used to prevent deflections of the relatively soft seal material. Three rods, each 
having a different surface finish, have been used throughout the experimental program. Values of some roughness parameters (according to DIN) obtained from surface profiles measured in the axial direction are given in table 1 .

Table 1. Roughness parameters from profiles in axial direction

\begin{tabular}{|l|l|l|l|l|}
\cline { 2 - 5 } \multicolumn{1}{c|}{} & $\operatorname{rod} A$ & $\operatorname{rod} B$ & $\operatorname{rod} C$ & seal \\
\hline $\mathrm{R}_{\mathrm{a}}[\mu \mathrm{m}]$ & $<0.01$ & 0.05 & 0.34 & 0.54 \\
\hline $\mathrm{R}_{\mathrm{z}}[\mu \mathrm{m}]$ & 0.06 & 0.36 & 2.6 & 3.8 \\
\hline $\mathrm{R}_{\mathrm{p}}[\mu \mathrm{m}]$ & 0.03 & 0.15 & 2.1 & 3.4 \\
\hline
\end{tabular}

An identical test program has been performed for the three rods used. The first part of this program was basically performed to establish friction-velocity curves at constant fluid pressure, both at instroke and outstroke. At instroke measurements, extra oil was supplied at the air side of the seal to eliminate the influence of different oil supply at the leading edge of the contact. At pressures of 2.5, 5, and 10 [MPa] motion patterns with constant velocity throughout 80 of the stroke of 300 [mm] were imposed on the seal housing. The velocity was varied according to the following range: 25,50 , $100,150,200,250,300,400$, and $500[\mathrm{~mm} / \mathrm{s}]$. The second part of the test program consisted of simultaneous measurements of friction and leakage at outstroke. They were performed at a pressure of 5 [MPa] and primarily within the velocity range, in which the friction-velocity curve displayed a non decreasing tendency. Using rod $B$ additional measurements of out-leakage at a pressure of $2.5[\mathrm{MPa}]$ have been performed.

\section{RESULTS}

The results of the friction measurements at instroke and outstroke for the different rods are given in figures 5,6 and 7 .

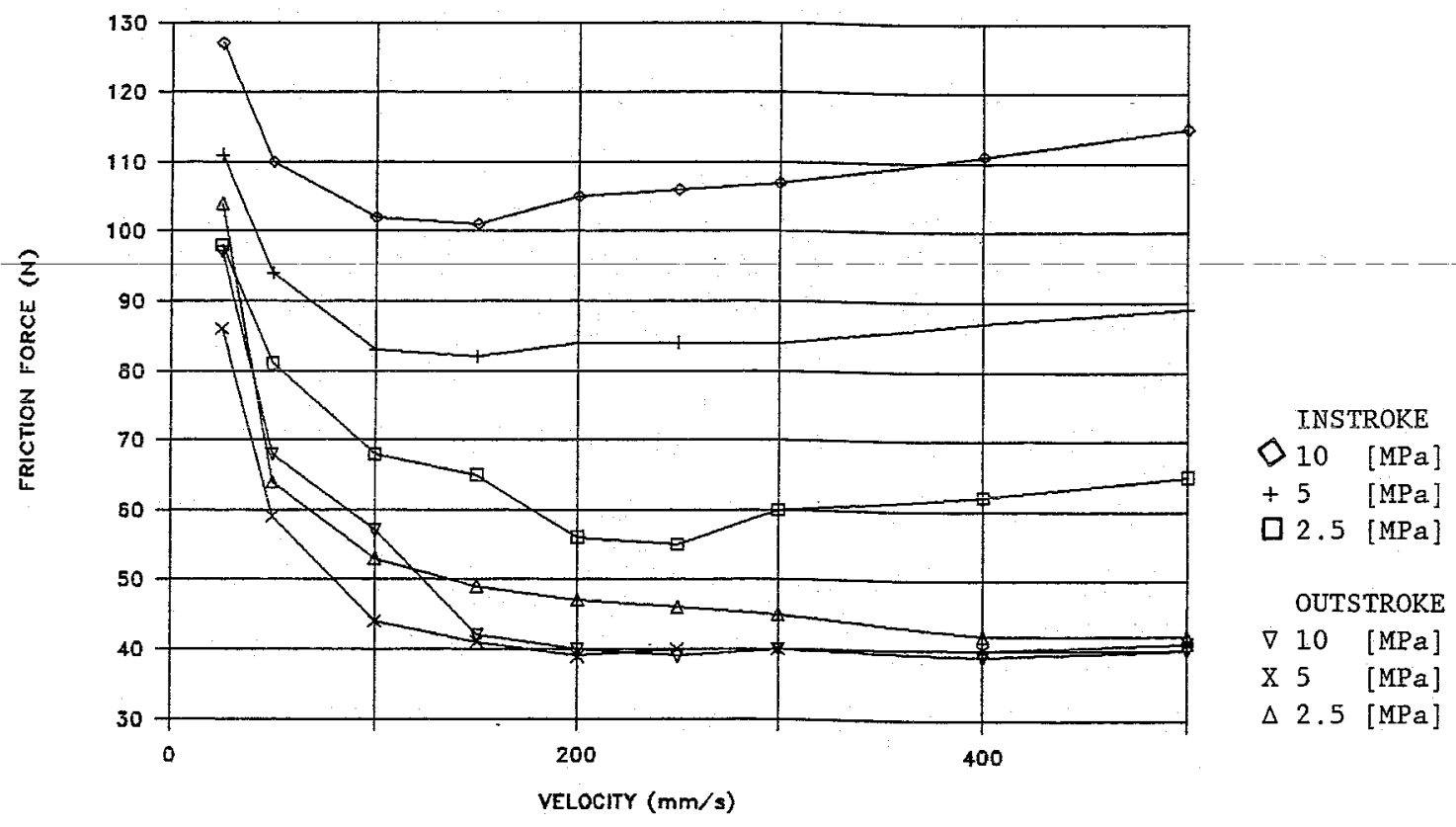

Fig. 5 Friction force $(\operatorname{rod} A)$. 


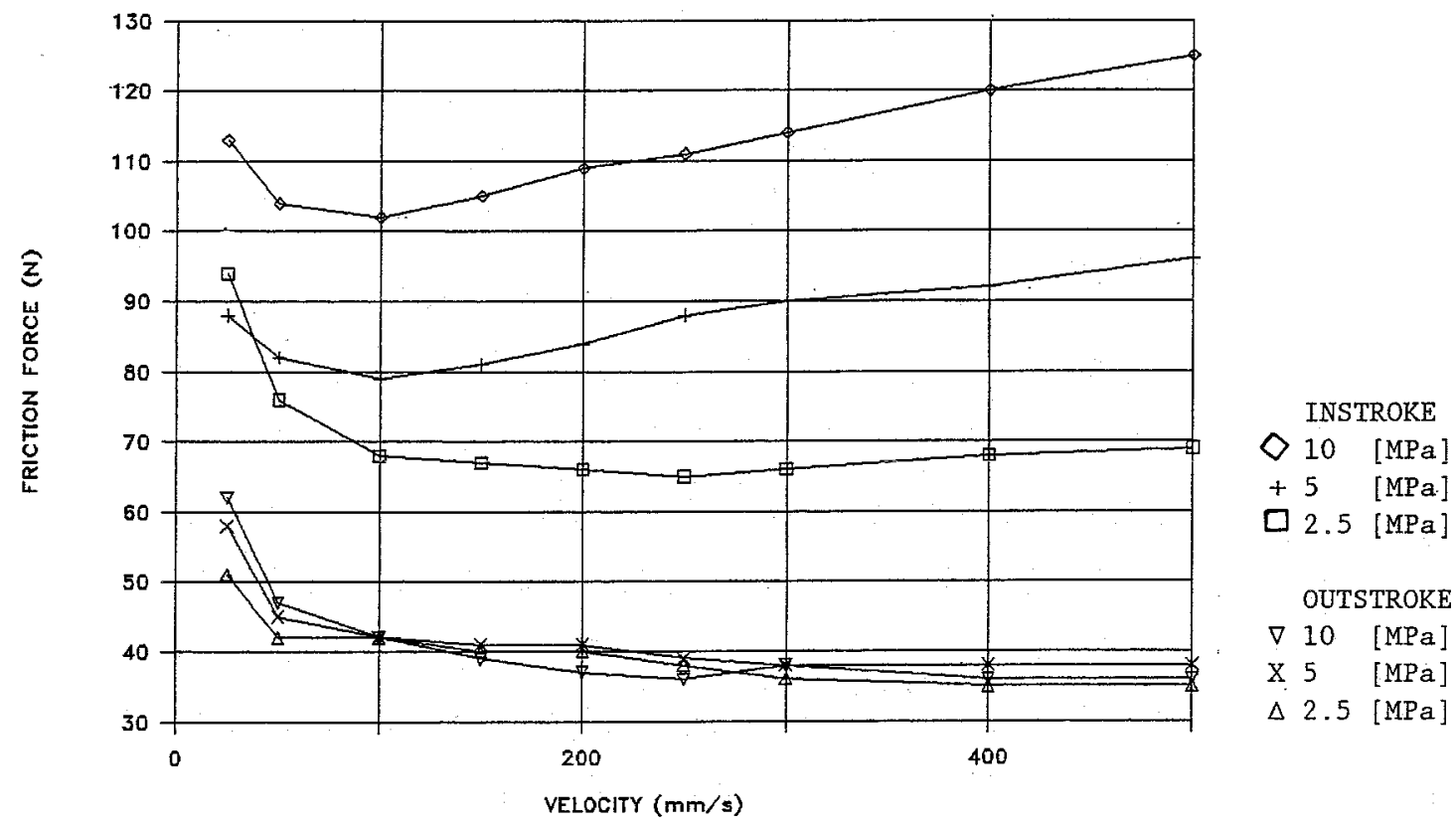

Fig. 6 Friction force (rod B).

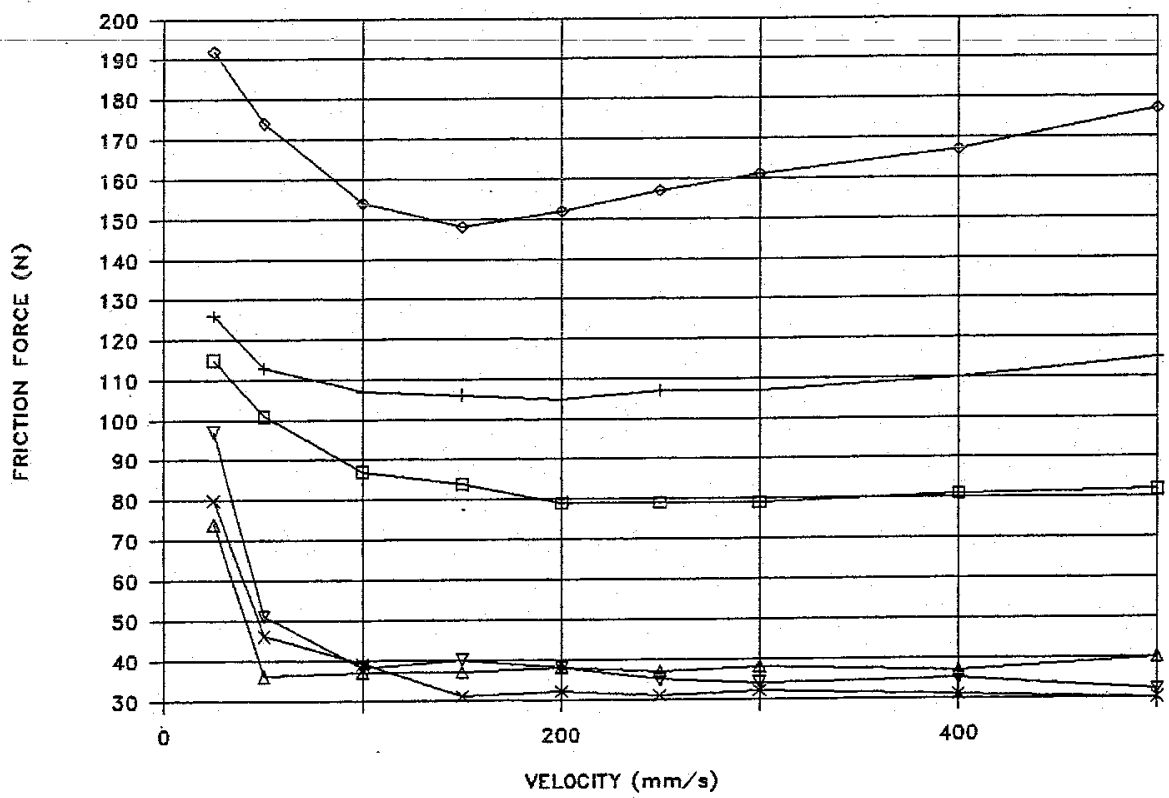

INSTROKE

$\checkmark 10 \quad[\mathrm{MPa}]$

+5 [MPa]

口 2.5 [MPa]

OUTSTROKE

$\begin{array}{lll}\nabla & 10 \quad[\mathrm{MPa}]\end{array}$

$X 5$ [MPa]

$\triangle 2.5[\mathrm{MPa}]$

Fig. 7 Friction force $(\operatorname{rod} C)$. 
The results of the measurements of outleakage at a pressure of $5[\mathrm{MPa}]$ for the different rods are presented in figure 8 . They are given as average thicknesses of the leaked film, which remains on the rod.
The results of the measurements of out-leakage at two different pressures of 2.5 and 5 [MPa] using rod B are presented in fig. 9.

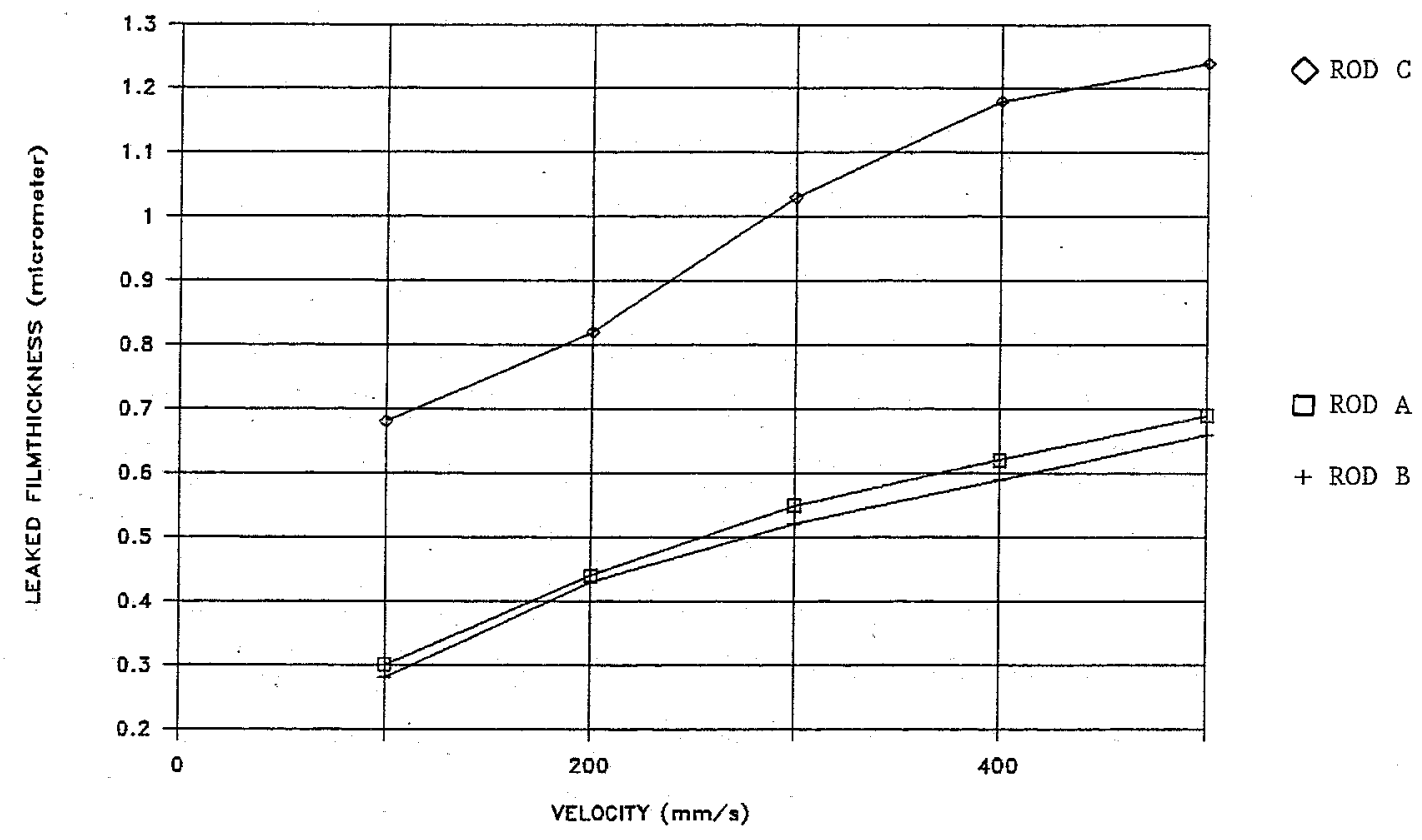

Fig. 8 Out-leakage using different rods at 5 [MPa].

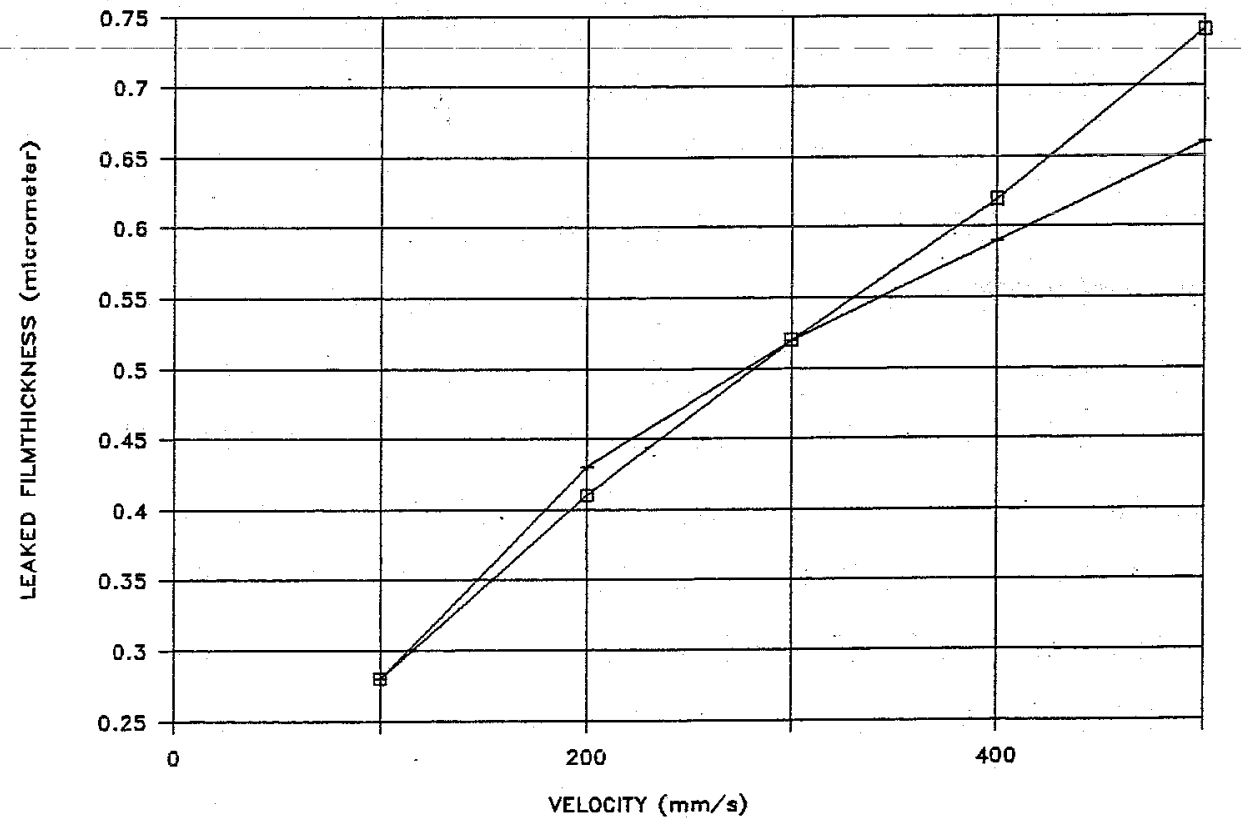

$\square-2-5-[\mathrm{MPa}]$

$+5[\mathrm{MPa}]$

Fig. 9 Out-leakage at 2.5 and $5[\mathrm{MPa}](\operatorname{rod} B)$. 


\section{DISCUSSION}

The experimental friction curves confirm the general frictional behaviour of elastomeric reciprocating seals as depicted in fig. 1. Significant differences are found between instroke and outstroke. The increase of friction at higher velocities is not found at outstroke. Furthermore, friction at instroke is much higher than friction at outstroke. The influence of pressure is remarkable. At instroke friction increases as pressure rises, but at outstroke friction is almost independent of pressure. Similar results were obtained by Field and Nau (6). They found a more pronounced difference in friction levels between instroke and outstroke and a decrease in friction with rising pressure at outstroke. The influence of surface roughness of the rod on friction at higher velocities at outstroke is small, friction decreasing slightly with increasing roughness. At instroke friction clearly increases with roughness. For both directions of motion differences between the results using rod $A$ and $B$ are small.

Out-leakage increases approximately with the square root of the velocity. From fig. 8 it appears that the influence of surface roughness of the rod on leakage becomes important only for the roughest rod $\mathrm{C}$. Using this rod leakage is found to be much higher than leakage using the relatively smooth rods $A$ and $B$. Using rod $B$ the influence of pressure on out-leakage is negligible (fig. 9). This result is qualitatively in agreement with the observed friction force (fig. 6).

The observed dependence of leakage on velocity is characteristic of smooth elastohydrodynamic lubrication. According to the inverse hydrodynamic Iubrication theory (14) the thickness $h_{0}$ of the lubricant film at the position, where the pressure gradient is zero and hence the velocity varies linearly over the thickness of the film, can be calculated from:

$\mathrm{h}_{0}=\left(\frac{8 \eta \mathrm{v}}{9\left(\frac{\partial \mathrm{p}}{\partial \mathrm{x}}\right)_{\max }}\right)^{0.5}$

In this formula $\left(\frac{\partial p}{\partial x}\right)_{\max }$ stands for the maximum pressure gradient in the direction of velocity at the position where simultaneously the film thickness equals $1.5 * h_{0}$. This position will occur at the leading edge of the lubricated contact. $h_{0}$ is directly related to the flow per unit of width through the lubricant film by:

$\mathrm{q}=\frac{\mathrm{vh}}{2}$

In a highly deformed contact the thickness of the elastohydrodynamic lubricant film may be approximated by $h_{0}$ over the major part of its length. Furthermore, in a stationary situation it is evident from conservation of mass that the thickness of the leaked film at outstroke, which remains on the rod and therefore relatively moves with velocity $\mathrm{v}$, must be equal to $0.5 \div \mathrm{h}_{0}$. Hence, assuming smooth film lubrication, an average film thickness in the seal contact may be calculated from leakage data by:

$\hbar_{c I}=2 \hbar_{1}=\frac{2 m}{\pi d 1 p}$.

Friction at outstroke calculated by viscous shear, using average film thicknesses according to formula (3), is small compared to measured friction. This comparison is presented in fig. 10 for the experimental results obtained at 2.5 and 5 [MPa] using rod B. Similar results may be found for the data obtained using rod $A$ and $C$.

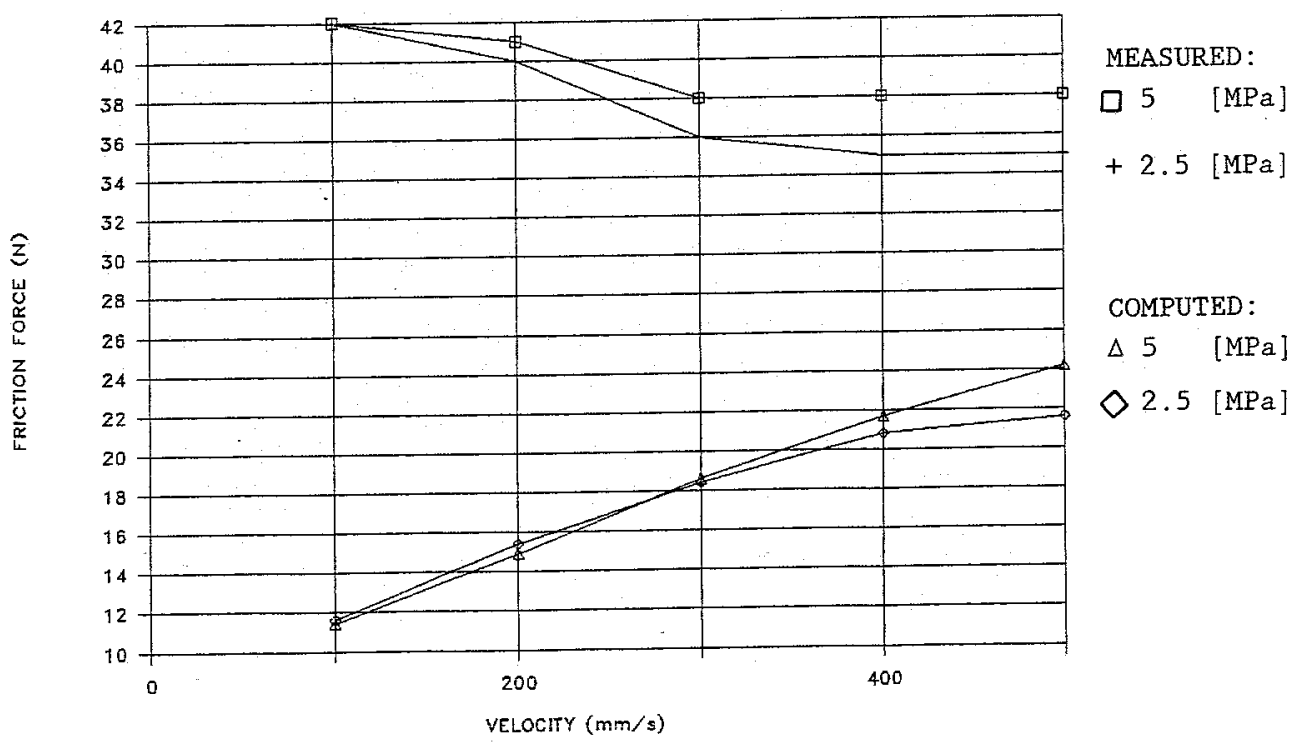

Fig. 10 Friction at outstroke calculated from leakage data assuming full film lubrication versus measured friction (rod $B$ ) 
Clearly, full film lubrication theory for smooth surfaces is not convenient to describe the lubrication of the sealed conact. This will not come as a surprise regarding the frictionvelocity curves, which imply mixed lubrication.

Until now, effects of surface roughness on the lubrication of the sealed contact have not received much attention. In particular the roughness of the seal surface has been disregarded, although commonly being considerably larger than the roughness of the mating surface. Probably it is often assumed that (most of) the roughness of the relatively soft seal disappears under the pressures in the sealed contact. However, for elastomeric materials the deformation of roughness asperities is mainly elastic. If the seal surface is (locally) lifted from its counterface by hydrodynamic effects, previously oppressed asperities may partly reappear. If this is true, then areas of contact may exist even at large nominal separation of the surfaces and consequently large leakage values, because of the dimensions of the (undeformed) roughness asperities (nominal separation is defined here as the distance between reference planes through the roughness height distributions of the mating surfaces). Both viscous shear and adhesion in the contact areas will hence contribute to friction.

At small velocities $(<50[\mathrm{~mm} / \mathrm{s}])$ the contribution from viscous shear will be small. The lowest friction then appears to be found using rod $B$. If the surface of the rod is smoother (rod A) the total area of contact is larger due to the diminished depth of the roughness valleys. Hence friction will be higher. If the surface of the rod is considerably rougher (rod $C$ ) hysteresis effects may become important, causing friction to increase.

As velocity increases, hydrodynamic effects become more important. The total area of contact diminishes; giving rise to the observed friction and leakage characteristics (fig. 5-9). At instroke, the increase in friction at rising velocity may be explained by the merely small variations in total area of contact at increasing separation, which might occur at small separation values. An other explanation may be the occurance of very thin lubricating films in contact areas due to macro-elastohydrodynamics (hydrodynamic-elastic effects on individual roughness asperities). Comparing the roughness of the rods to that of the seal explains the small differences in observed friction and leakage obtained using $\operatorname{rod} A$ and $B$. Using the very rough rod $C$ out-leakage is higher and friction at outstroke is lower due to additional transport of oil in the roughness valleys of the rod. However, at instroke friction is higher, possibly due to increased draping of the elastomeric seal material over roughness asperities of the rod, thereby increasing the contribution of hysteresis.

\section{CONCLUSIONS}

A test rig has been designed to investigate the tribological behaviour of reciprocating seals. Furthermore an accurate method for the measurement of leakage has been developed.

Friction and leakage measurements have been performed on a polyurethan seal, having a rect. angular cross-section with a single rounded edge, using three rods with different surface roughness. The results indicate that it is not convenient to employ EHL theory for smooth surfaces to describe the lubrication of the sealed contact. In the case of rod seals, primarily developed for minimizing leakage, it may be expected that this is often so.

The results may be explained by considering the influence of surface roughness. In particular the relatively large roughness of the seal surface seems important. Measurements using seals with different surface roughness are sceduled for the near future.

For a better understanding of the tribological process in the sealed contact, film thickness measurements appear to be very important. Current film thickness transducers are not very accurate and, because of their dimensions, are probably unable to distinguish between mixed and full film lubrication. Research on film thickness measurements is currently being performed and will be the subject of a future paper

\section{ACKNOWLEDGEMENT}

We thank Mr. J. Peels for his indispensable assistance during the experiments. We also thank Parker-Prädifa (Germany) for supplying the test seals.

\section{References}

[1] FIELD, C.J. and NAU, B.S., 'A theoretical study of the elastohydrodynamic lubrication of reciprocating rubber seals', ASLE Transactions, Vol 18, No 1 , 1974, pp. 48-54

[2] RUSKELL, L.E.C., 'A rapidly converging theoretical solution to the elastohydrodynamic problem for rectangular rubber seals, J. Mech. Eng. Sc., Vol 22, No 1, 1980, pp. 9-16

[3] YANG, Y. and HUGHES, W.F., 'An elastohydrodynamic analysis of preloaded sliding seals, ASLE Transactions, Vo1 27, No 3, 1983, pp. 197-202

[4] PRATI, E. and STROZZI, A., 'A study of the elastohydrodynamic problem in rectangular elastomeric seals, Journal of Tribology, Vol 106, October 1984, pp. 505-512

[5] FIELD, C.J. and NAU, B.S., 'An experimental 'study of reciprocating seals', Proc. Conf. on Elasto Hydr. Lubr., organised by the Inst. Mech. Eng., 1972, paper C5, pp. 29-36 
[6] FIELD, C.J. and NAU, B.S., 'Film thickness and friction measurements during reciprocation of a rectangular section rubber seal ring', 6th Int. Conf. on Fluid Sealing, 1973, paper C5, pp. 45-56

[7] FIELD, C.J. and NAU, B.S., 'The effects of design parameters on the lubrication of reciprocating rubber seals', 7th Int. Conf. on Fluid Sealing, 1975, paper C1, pp. 1-13

[8] SCHRADER, K., 'Beitrage zur Klärung des Abdichtvorganges Gummi-elastischer Abdichtungen axial verschiebbarer hydrostatischer Bauteile', Ph. D. Thesis, Dresden Univ. of Technology, 1978

[9] AUSTIN, R.M., FLITNEY, R.K. and NAU B.S., 'Contact stress friction and the lubricant film of hydraulic cylinder seals', 8 th Int. Conf. on Fluid Sealing, 1978, paper J2, pp. $11-20$

[10] WERNECKE, P.W., 'Untersuchung der physikalischen Vorgänge in Spalten von Hydraulikdichtungen', Ph. D. Thesis, Aachen Univ. of Technology, 1983

[11] WERNECKE, P.W., 'Analysis of the reciprocating sealing process', 11th Int. Conf. on. Fluid Sealing, 1987, paper El, pp. 249-277

[12] VISSCHER, M., 'Filmdiktemeting op de meetopstelling voor translerende afdichtingen' ('Measurement of film thickness on the reciprocating seals test rig'), M. Sc. Thesis, Eindhoven Univ. of Technology, 1987

[13] STRUIK, K.G. and MUCHANG, F., 'Measurement of shape abd roughness by a modified compact disc sensor coupled to a personal computer', 4th Int. Seminar on Precision Engineering, Cranfield Inst. of Technology, UK, 11-14 May, 1987, pp. 81-90

[14] BLOK, H., 'Inverse problems in hydrodynamic lubrication and design directives for lubricated flexible surfaces', Proc. Int. Symp. Lubr. and Wear, by D. Muster and B. Sternlicht (eds.), Houston, 1963, pp. 9-151 